\title{
Two Web-GIS Projects on Russian Historical Sources of the 15-19th Centuries
}

\author{
Aleksei A. Frolov, ${ }^{a}$ Aleksei A. Golubinskiy ${ }^{b}$ \\ ${ }^{a}$ Institute of World History, Russian Academy of Sciences; npkfrolov@gmail.com \\ ${ }^{b}$ Institute of Russian History, Russian Academy of Sciences; Russian State Archive of Ancient Documents; lexus.gol@gmail.com
}

\begin{abstract}
The paper describes an experience of online-publication of Russian archival materials by means of two webGIS projects. The first project is devoted to publication of the collection of the earliest Russian cartographic drawings (mainly 2nd half of the 17th century), which cover a significant part of Russian territory, mainly the European part (http://rgada.info/geos2). Most of them have never been published and were not easily accessible for scholars and users due to poor physical condition. We tried to combine opportunities of geocoding of the picture with capacity to use an authentic image. The second project offers the results of localization of toponyms and land parcels from various documents (15-19th cc.) connected with one region of the Russian State called Bezhetsk Upland (http://rgada.info/bezheck/popup.html). These results were arranged in the set of layers which may be combined by the user.
\end{abstract}

Keywords: Russian cartography, 16-17th centuries, Geographical information, Historical sources, Cartographic drawings, Archival publication, Settlement structure, Web-GIS, General Survey, Boundaries.

\section{Introduction}

The mapping of historical data related to the pre-Modern period has its own specifics. First, as a rule spatial coordinates of objects may be specified only with great approximation. Second, when comparing the objects of one chronological layer, it is necessary to have an idea about historical context in which these objects existed. When comparing the sets of diachronic data, we should know what kind of deformation of the historical context happened within the timeline.

We want to share an experience of online-publication of Russian archival materials by means of two web-GIS projects. They have different tasks and contexts, but both GIS projects are based on historical documents of Russian State Archive of Ancient Documents. Both projects had been carried out by the Laboratory of Historical Geoinformatics at the Institute of World History (Russian Academy of Sciences) in collaboration with Russian State Archive of Ancient Documents. The lion's share of historical sources that had been used in the projects are stored in this archive. The financial support was granted by Russian Scientific Foundation and Russian Foundation of Humanities.

Common goals of these projects were as follows: 1) to publish unique archival materials about Russian history; 2) to elaborate a technique of online publication on the basis of GIS-technology; 3) to study the published materials as sources on historical geography.

\section{Web-GIS project "16th- and 17th-century Drawings of the Russian State" (http://rgada.info/geos2/)}

This project is devoted to publication of the collection of the earliest Russian cartographic drawings (mainly the 2nd half of the 17 th century). The online publication is a significant step in insuring safety of archival documents. It is especially important for the earliest Russian cartographic materials. Providing online availability of archival information is a courageous experiment for which only few archives in the world feel ready. The whole collection com-prises about 1000 documents. Most of them have never been published, and they are not easily accessible for scholars and users. The Catalogue of these artifacts was prepared by Vladimir Kusov (Kusov, 2007). This Cata-logue formed the basis of our work. The drawings in the Catalogue are most valuable for public viewing for the "geographic information" they hold, i.e. symbolic representation of settlements, forests, lakes, roads etc. For this rea-son, integration of these drawings with a cartographic basis is a central point of our publication.

On the other hand, geographical context facilitates using textual information from these documents in various sorts of studies such as investigation of social relations (Kivelson, 2006), reconstruction of the facades of churches, that have disappeared over time (Nikolaeva, Sirotkin, 2017), studying of historical Russian town planning (Vorotnikova, Nedelin, 2013), changes in landscape, etc.

There are many internet resources in the world currently sharing historical maps. But most of them are dealing with small-scale images or drawings that may be easily geocoded by popular transformation algorithms. Russian drawings of the 17 th century were not made on a mathematical basis, usually they have no universal scale. Most of them are pictures or large scale schemes made by the visual method. Usually the craftsman had no goal to con-strain proportions with which real objects were connected. Literally, "geocoding" cannot be applied to 
these arti-facts. Some attempts to correlate recognizable points of the image with landscape features on the map show that, in many cases, the result changes the initial image beyond recognition (Fig. 1). So it cannot be effectively used to re-late the images with a map. As a result, our decision was to use only a primitive transformation algorithm (Helmert transformation) that could demonstrate only approximately the positions of objects depicted on the drawing. Two pairs of points were enough to "georeference" a drawing (Fig. 2).

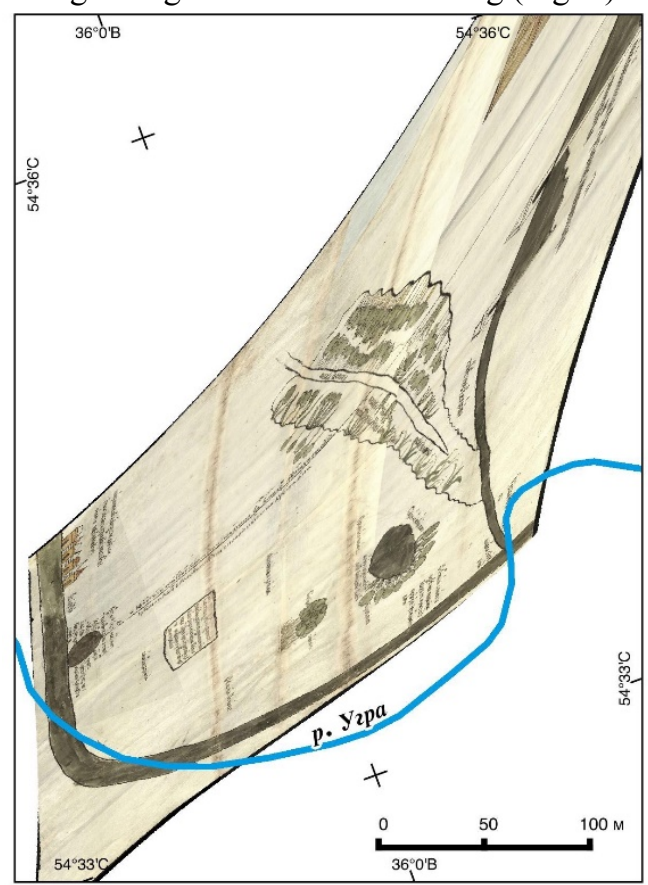

Fig. 1. Distortion of the canvas of drawing by "thin plate spline" algorithm (drawing 303 by V.S. Kusov).

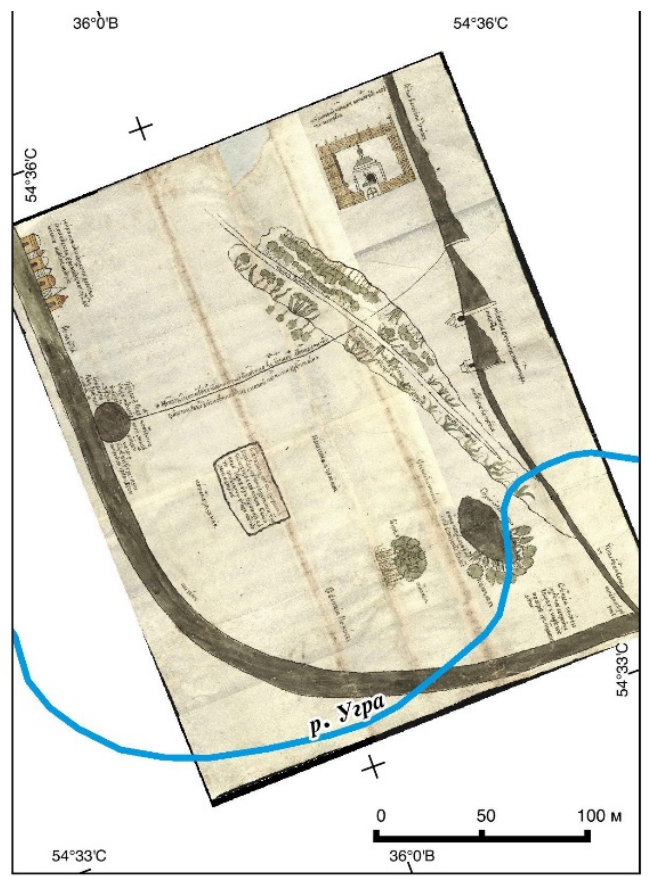

Fig. 2. Distortion of the canvas of drawing by Helmert algorithm (drawing 303 by V.S. Kusov).

For more precise and informative relation of the image with a map, we have omitted geocoding of the raster. For each drawing that could be correlated with locality, we created vector polygons which approximately covers the ter-ritory depicted on the drawing. First, we explored objects lying at the edges of the drawing to find them on a map (Fig. 3). The current and historical state of the area was analyzed using a number of cartographical resources pub-lished on the Internet (http://www.marshruty.ru/, https://yandex.ru/maps/, https://www.google.ru/maps/, http://www.etomesto.ru/ etc.). Whenever possible data of the General Land Survey (dated from the middle 18th to the 19th century) were also used. So we traced margins of the depicted locality, taking into account relief and other features of landscape, names of heathlands and natural boundaries. Some polygons have a very sophisticated con-figuration which demonstrates the appropriate degree of distortion of reality that the drawing has (Fig. 4).

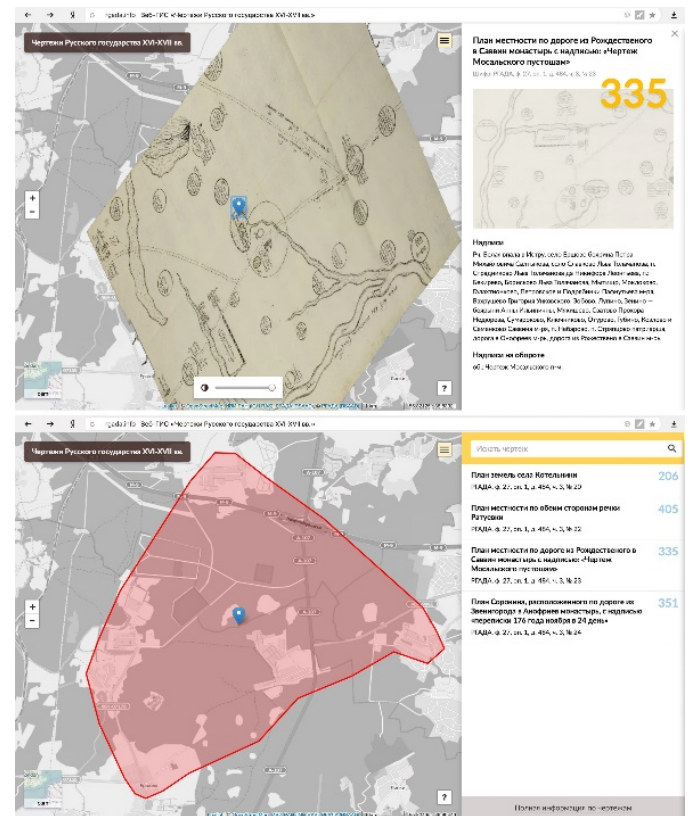

Fig. 3. Correlation between image and map (drawing 335 by V.S. Kusov).




Fig. 4. Degree of distortion of reality in drawings (drawing 927 by V.S. Kusov).

In 2014-2016, we managed to localize more than 700 Russian drawings of the 17 th century. All the results are integrated into the web-GIS: http://rgada.info/geos2/. The project materials are represented in three dimensions.

\subsection{Basic dimension}

The basic dimension (Fig. 5) is represented by a map with a layer of pins marking centroids of polygons (the left part of display) and a table with brief information about each drawing (the right part of display). In many cases, several polygons overlap or intersect each other on map. Sometimes, they are situated in close neighborhoods to one another. To make perception of the appropriate pins better, we used clustering. The color of clusters differs from the amount of pins that the cluster united. The clustering changes during scaling the view. The pink polygon with red contour emerges when the mouse pointer appears over the pin. The click on the pin brings the georeferenced raster. Its transparency is flexible and changes by the scroll bar. OpenStreetMap substrate layer facilitates the orientation of the polygon and raster in relation to the locality. The user may choose among three variants or switch them all off.

The brief information table is provided by the search line. The search tool helps to find any specified drawing by text fragment contained in basic sections of the drawing description. The data about chosen drawing appear on the place of the brief information table (the right part of display). Besides textual data one can find here a preview image of the drawing.

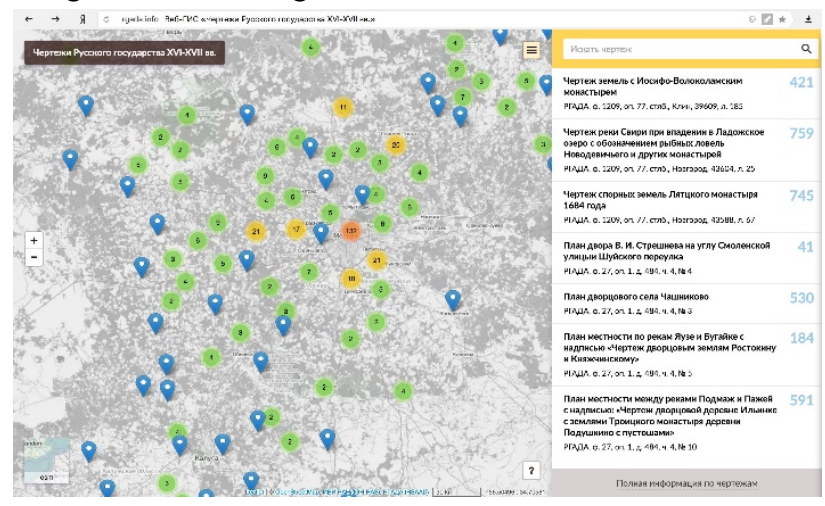

Fig. 5. Homepage of the web-GIS project "16th- and 17thcentury Drawings of the Russian State".

\subsection{Full-text view}

For more details about the drawings, users can go to the full version of the table and use the text filter to search in every specified field (see Fig. 6). These fields are as follows (mainly according to Kusov with some supplements): Catalogue number, Title, Archival Code, Size, Art Technique, Watermarks, Comments About Artifact, Lower Date, Upper Date, Conventions, Text on the Front Side, Text on the Revers Side, Bibliography, Context of the Document. From any record, the user may go to the map space by click. In this case, the map becomes centered by the chosen drawing.

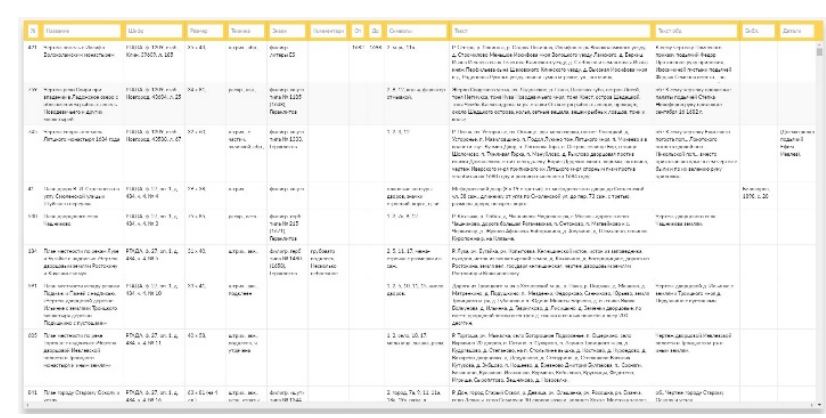

Fig. 6. Full version of the table of attributes of Russian drawings with text filters for search.

\subsection{Large format image view}

The third dimension of the project is represented by the large format image which may be accessed in a separate window by clicking on the preview image in the right part of display. The large format image is not transformed by geocoding. The window is provided by toolbox to facilitate the navigation: zooming, moving, rotation (Fig. 7).

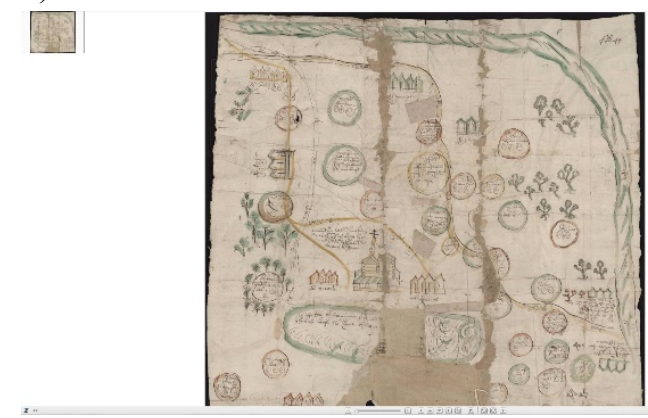

Fig. 7. Large format image of drawing with tollbox for navigation.

\subsubsection{The preliminary results of the project:}

We introduced, for scientific use, a significant part of the Russian drawings that had been preserved since the 16th and 17th centuries, about 1000 artifacts are described in the table, about 700 of them were mapped. This resource attracts the attention of scholars (historians, cartographers, geographers and others), and all people interested in geographic information of historical sources; We elaborated methods of publication of historical materials via GIS technologies, and we discovered the original technique of tracing the area depicted on the drawing by means of polygons covering the appropriate locality;

We accomplished some studies about Russian preModern drawings as a historical source.

\subsubsection{The immediate prospects for the project}

While working on the project, we realized that simple reproduction of drawings online cannot guarantee relevant perception of the text for the majority of users. The handwritings of the 17 th century are not always easily read even by an experienced archaeographer. Besides that the content of our table was taken from the Catalogue, which reflects the text of drawings in far from complete form. So the next task is to include a comprehensive annotation of drawings in the table. It is important to find a way to tie each text fragment with the 
appropriate area of the drawing canvas. As for the webGIS interface, we are going to increase its functionality, i.e. to add tools for filtering by chronology and for loading and unloading objects by timeline, to include layers with historical administrative divisions and historical centers. Certainly, we will continue to study Russian drawings as historical sources.

\section{Web-GIS project "Sources for historical geography of Bezhetsk Upland" (http://rgada.info/bezheck/popup_eng.html)}

This project integrates data taken from various historical sources of the 15 th-19th centuries about temples, settlements and heathlands, borders of the land property, and other objects for the territory of $9000 \mathrm{sq}$. km. The region called Bezhetsk Upland is situated in the Mologa river basin between Moscow and Novgorod the Great (Fig. 8). In Russian historiography, it attracts attention of scholars due to the complex nature of agrarian colonization and availability of sources for the history of landowning structures since the 15th century. All speculations could appeal only to very generalized geographical data about the region thus far. The further historical geography exploring of the region might be continued only via introducing, for scientific use, implicit geographical information from historical sources.

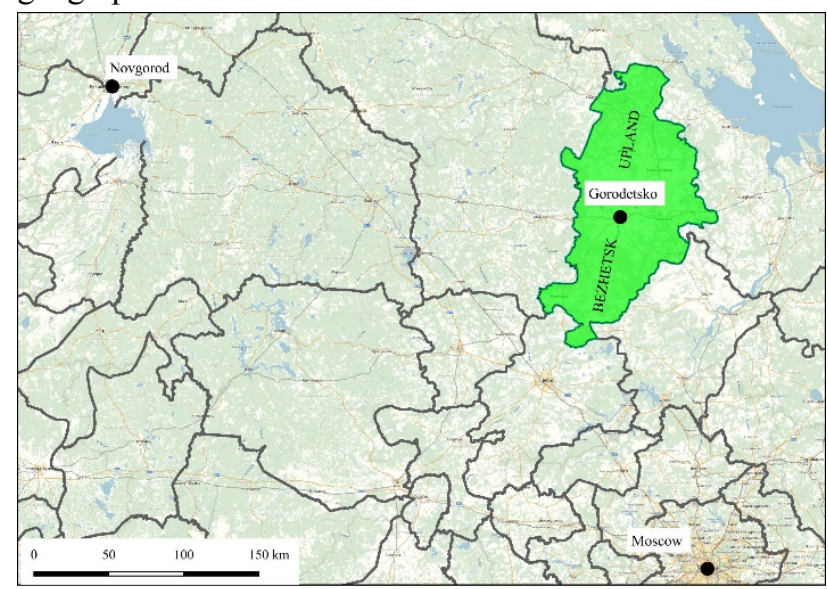

Fig. 8. Historical region "Bezhetsk Upland" on contemporary map (grey lines represent administrative division of Russian state circa 1600 A.D.)

The General Survey maps and plans (the late 18th century) were used as a cartographic base for study. The plans were made in scale $1: 8$ 400. Each plan corresponds to one land parcel. Each parcel had its own history of land-owning. The borders of the parcel were unique and sometimes sophisticated. During surveying the contour of the parcel was measured by distance and azimuth, internal space of the plan was depicted visually. These plans are rather simple. They have low precision but they fixed positions of toponyms in the space.

To create the initial network of polygons for each parcel of land, we tried primarily to use plans of district (ouezd) from the late 18th century of the General Land Survey (1 : 42000). But our experience of "geocoding" them showed significant inaccuracies, so we had to involve maps of Mende Survey (the middle 19th century). This solution is based on the fact that the General Survey maps served as a compendium for maps prepared on the mathematical base by general Mende. This connection facilitated the localization of about 9000 names possessed by objects registered by General Land Survey in Bezhetsk Upland (Fig. 9).
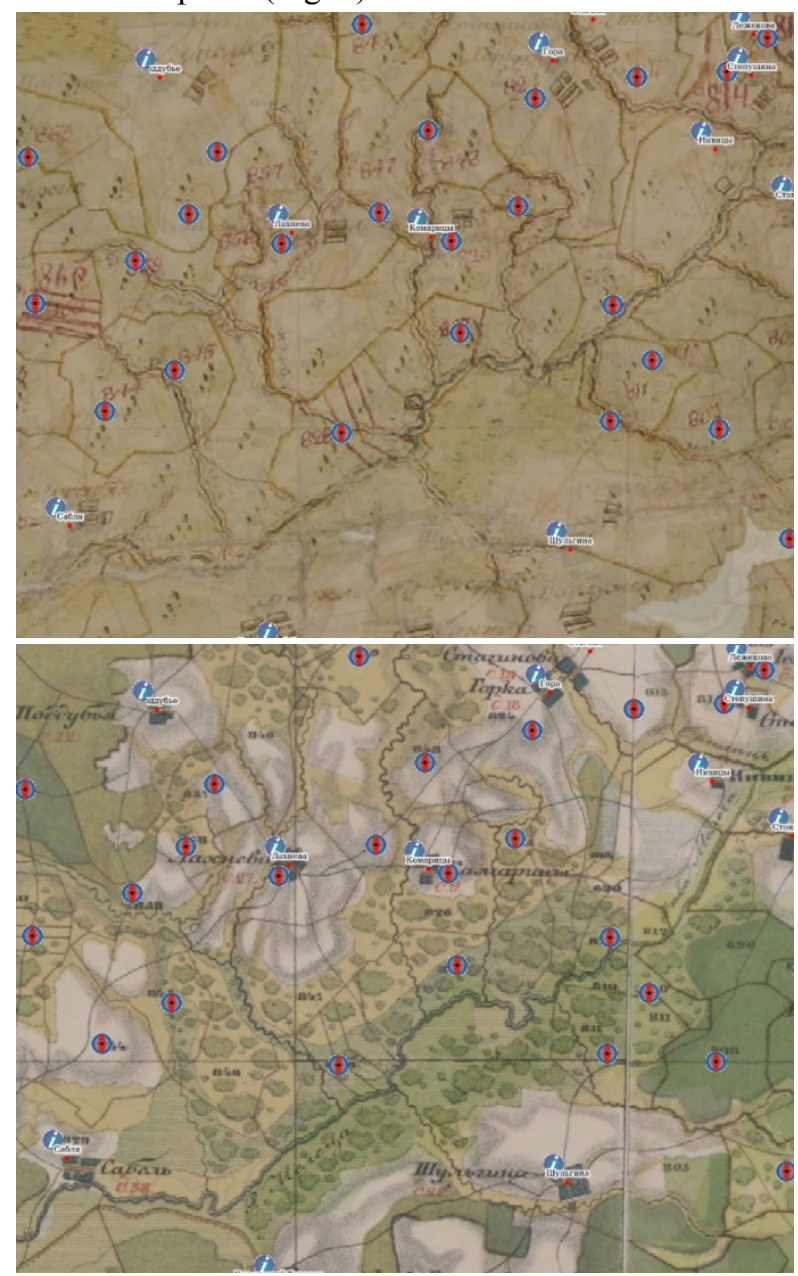

Fig. 9. Historical objects from the 17th century sources on cartographic base (atlases) of General Land Survey (the late 18th c.) and Mende Survey (the middle 19th century).

The 17 th century history sources used were:

a) book of survey of 1627-1629 on manorial and allodial lands of Bezhetsk Upland from the inquiry and survey led by Danila Svechin and Fedor Vtoroy the podyachy (clerk) - Russian survey tradition of the 17 th century implies taking into account personalities of creators. (Russian State Archive of Ancient Documents - RSAAD. Archive fund 1209. Bk. 23);

b) cadastre of 1627-1629 of manorial, allodial and abandoned lands in Bezhetsk Upland from the inquiry and measure led by D.P. Svechin (RSAAD. Archive fund 1209. Bk. 24, parts 1 and 2);

c) census book of 1646-1647 of homesteads in Gorodetsky town, and manorial and allodial villages and house-holds in Bezhetsk Upland from the scouting and census led by I.D. Kolychev's and J. Fedorov the podyachy (RSAAD. Archive fund 1209. Inventory $1 . \mathrm{Bk} 25)$; 
d) census book of 1677 of homesteads in Gorodetsky town, and manorial and allodial villages and households in Bezhetsk Upland from the census led by D.G. Tiutchev and V. Yakovlev the podyachy (RSAAD. Archive fund 1209. Inventory 1. Bk 11440);

e) book of cadaster and survey of 1686 on the Gorodetsky countryside from the inquiry and survey led by Fedor Polenov and Timofey Pavlov the podyachy (RSAAD. Archive fund 1209. Inventory 1. Case. 279. L. 507-525);

f) Russian drawings of the 17 th century relating to the territory of the Bezhetsk Upland.

A scouting description of the temples of Gorodetsky tithe executed by Dolmat Tishnev in the mid-1570's is a valuable source of historical geography of the Bezhetsk Upland of the 16th century.

Also data on 57 Bezhetsk charters of the late 14th - early 16th century (Moscow, 1952-1964. Vols. 1-3) were used in the work.

All these historical sources have their specific structure and content. They were compiled for different purposes. Nevertheless the toponyms they contain may be correlated and "geographical information" from each of them may be complemented. As a result, we have toponymic net that may be stratified to many chronological layers.

Localization of historical objects is a particular research task. As a rule, it is executed by retrospective mapping when objects from early maps are compared with precisely localized objects of modern maps and the objects from early written sources are compared by names and other characteristics with objects on historical and modern maps. The connections between synchronic objects caused by a historical context and the continuity of diachronic objects changing the name and contents over time are considered.

Geolocation of historical objects by means of retrospective method has one feature that clearly differs thematic historical maps from contemporary ones. Each object of the historical map that has not survived up to the middle 19th century may be geolocated largely conditionally. The precision of this localization may be assessed by various ways. Mostly, it depends on the status the object had on the basic General Land Survey map. If it was a settlement, the object may be found on the map rather precisely. But the majority of General Survey objects had a status of wasteland. In this case, the position of the appropriate settlement which had existed here in the 15 th-17th centuries may be determined only within the General Survey parcel that possessed this wasteland. That means the objects within the largest parcel may be located with the worst precision. This point seems to be very important if we have a goal to make a settlement structure model. We cannot ignore uneven precision of localization when studying fea-tures of this structure and its interaction with landscape.

Besides objects from the contemporary map (OpenStreetMap), our web-GIS contains geocoded maps of the 18th and 19th centuries, drawings of the 17th century, data about settlements and wastelands, and land parcels of the 15th-17th centuries (Fig. 10). These results are arranged in the set of layers which may be combined by the user in the web-browser. Data extracted from each historical source are compounded in a particular layer. To manage data from the web-GIS, one may use a search mechanism which responds to both text and graphic queries.

The layers that demonstrate changes in historical context at a particular moment include administrative centers and borders. Now these substances are in the making.

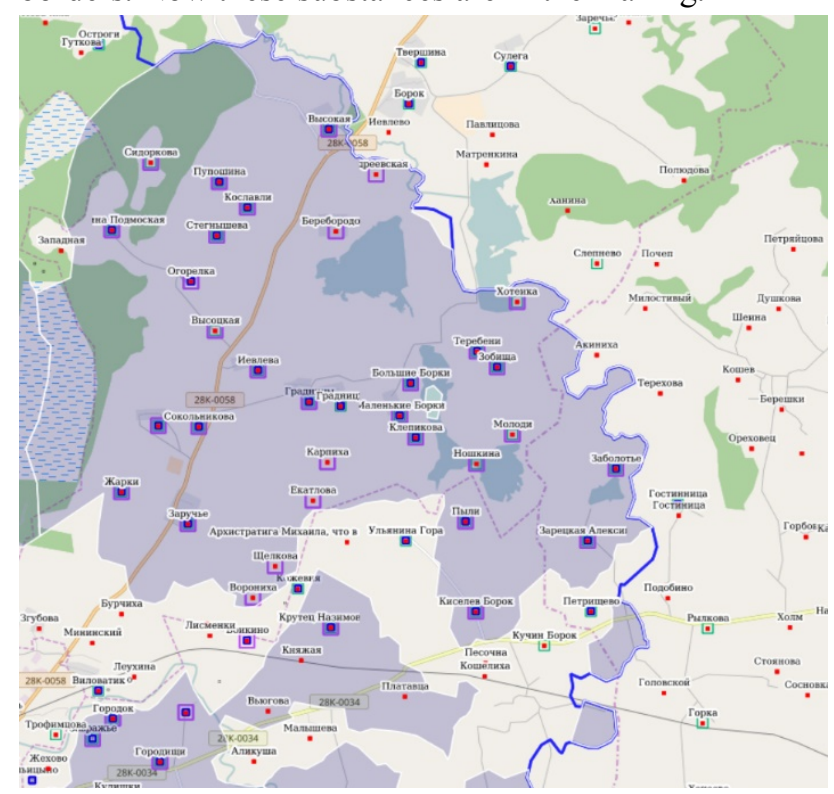

Fig. 10. Historical objects from the different 17th century sources on the map (fragment).

\subsection{The preliminary results of the project:}

We introduced, for scientific use, a set of materials on historical geography of the large region in Central Russia. Mainly the used sources have never been published, so that insures access to archival documents. Physical conditions of some of them do not allow them to be placed at the disposal of researchers. Now any regional studies on the history of the 15 th-19th centuries may be supported by data of this web-GIS;

We developed methods of localization of objects from written historical sources based on retrospective mapping and correlation of diachronic facts about one locality;

We reconstructed rural settlement structures of the region for the 15th-19th centuries. The resource is already facilitating studies of landowning of the 15 th -16 th centuries, Karelian migrations of the 17 th century, administrative histo-ry and transport infrastructure of the 15th-19th centuries.

\subsection{The immediate prospects for the project}

The next step forward should lead to the historicalgeographic atlas of Bezhetsk Upland which integrates histori-cal data of the 15th-19th centuries. Data of several historical sources will be added to the project. They will be taken into account when localizing datasets of the sources that had been already involved in the project 
before. Besides point layers marking positions of settlements and wastelands for different years, we are going to create some polyg-onal layers which are demonstrating distribution of lands among landlords and administrative divisions of the re-gion. Some linear layers are going to mark "major" roads and rural roads. These data may provide ordinary infor-mation for any historical atlas. Since we deal with sources that incompletely cover the region, the project would be-come much better if we separate areas that have relevant data from the source. It is very important for the source study.

\subsection{Some technical aspects of the both projects}

desktop GIS software - QGIS (installation boxes by OSGeo, NextGIS, QGIS KyngChaos);

operation system of the server - Ubuntu 14.04 LTS;

projection - EPSG:3857;

raster files - GeoTiff, six pyramids, stored on NextGISWeb server, downloaded via NextGISManager;

vector files - *.shp and *.GeoJSON, stored on NextGISWeb server;

spatial library - OpenLayers 3 and Leaflet (now we are planning to cross-over the first project to Leaflet as well);

to accelerate the download of polygons and rasters to the client and reduce the traffic they should be swapped only after choosing the pin by click;

exchange by text data via GeoJSON using Javascipt and PHP;

large format images are disposed on the base of Zoomify PRO.

\section{Acknowledgements}

We are grateful to Russian State Archive of Ancient Documents and personally to its director M. Ryzhenkov. Also we appreciate help of our colleagues - T. Bazarova, A. Deduk. I. Ankudinov, A. Sirenov, N. Bashnin and NextGIS company.

\section{References}

Kivelson, V. (2006). Cartographies of Tsardom: The Land and Its Meanings in Seventeenth-Century Russia. Ithaca and London: Cornell University Press.

Kusov, V.S. (2007). Moskovskoe gosudarstvo XVI nachala XVIII veka. Svodnyj katalog russkih geograficheskih chertezhej. Moscow: Russkij mir.

Nikolaeva, M.V., Sirotkin, S.V. (2017). Geograficheskij chertezh Nizhnego Novgoroda i ego okrestnostej 1750 g.: novyj istochnik po istorii cerkovnogo zodchestva Nizhegorodskogo i Balahninskogo uezdov ili nepritjazatel'nye risunki komissara Glavnoj dvorcovoj kanceljarii Aleksandra Semenova. Arhitekturnoe nasledstvo (in printing).

Vorotnikova, I. A., Nedelin, V. M. (2013). Kremli, kreposti i ukreplennye monastyri Russkogo gosudarstva XV-XVII vekov. Moscow: Booksmart. 